\title{
A Bibliometric Review of the Knowledge Base for Innovation in Sustainable Development
}

\author{
Ronald Vatananan-Thesenvitz ${ }^{1, * \mathbb{C}}$, Amaury-Alexandre Schaller ${ }^{1}$ and Randall Shannon ${ }^{2}$ \\ 1 Institute for Knowledge and Innovation-South-East Asia (IKI-SEA), Bangkok University, Bangkok 10110, \\ Thailand; amaury.schaller@gmail.com \\ 2 College of Management, Mahidol University (CMMU), Bangkok 10400, Thailand; Randall.sha@mahidol.ac.th \\ * Correspondence: Ronald.t@bu.ac.th
}

Received: 27 July 2019; Accepted: 20 September 2019; Published: 18 October 2019

\begin{abstract}
This review explores the rising research field of sustainable development in combination with innovation. The basis to reach sustainable development is innovation, which plays a role on all dimensions, be it economically, socially, or environmentally. In this review, science mapping techniques were employed in order to asses 1690 journal articles extracted from the SCOPUS database concerned with innovation in sustainable development (ISD). The main objective of the review is to reveal the size, growth trajectory, and geographic distribution of the ISD literature. Furthermore, the aim is to assess the key publishing journals, authors, and documents as well as to uncover the intellectual structure and topical foci of the research domain. The review acknowledges a reasonable body of knowledge spanning nearly three decades. A result of this review is that the sustainable development literature emerged from the environmental research field and that the topical foci of the domain is closely aligned with the sustainable development goals (SDGs) set by the United Nations. This review is a first attempt to systematically analyze the literature on innovation in sustainable development (ISD) by applying science mapping techniques such as bibliometric analysis. It shall give guidance for future research and demonstrate the practical implications.
\end{abstract}

Keywords: sustainable development; sustainable development goals (SDG); innovation; sustainability; science mapping; bibliometric review

\section{Introduction}

In today's knowledge-based economy, in order to achieve sustainable competitive advantage, it is essential to innovate constantly [1]. Globalization has altered the economy of each society [2]. Nowadays, countries are connected in new ways, and knowledge, technologies, information, financial capital, and markets are denationalized, giving the possibility for each society to access more of everything. Inflexible nations or industries, who resist against globalization will suffer significant opposition in becoming more sustainable. Environmental issues such as water, soil, and air pollution, excessive land use, biodiversity loss, as well as resource depletion endanger the Earth's life support system [3-5]. Challenges such as poor working conditions, high unemployment, widening inequalities, the poverty trap, social vulnerabilities, as well as the inter- and intragenerational inequity, represent a big threat to societal balance [6-8]. Moreover, economic challenges as problematic ownership structures, flawed incentive structures, deregulated markets, and supply risk endanger the financial and economic stability for organizations and even whole societies [3,9]. In this context, the concept of the Circular Economy gained widespread attention on the agenda of politicians and peace-keeping organizations [10]. At the core of the concept lies the idea of minimizing waste and the reutilization of resources. The regenerative approach still allows the business model to be profitable by reusing, 
remanufacturing, recycling, and repairing different resources. The concept is in contrast to the linear economy, which has a wasteful approach to the production model.

The economist Thomas Robert Malthus (1766-1834) is considered to be one of the first to note that growth might one day reach its limits [11]. He based his assumption on resource scarcity, especially on the limits of good quality agricultural land, and hence the resulting decrease in agricultural output [12]. In the same vein, David Ricardo (1772-1823), who agreed with the population theory of Malthus, also foresaw the limits of economic growth due to a scarcity of natural resources. However, both economists did not include in their consideration technological innovations. Those innovations "have shifted the total production curve upwards, increasing output per unit of input and offsetting, but not eliminating, the tendency towards diminishing returns" (p. 499, [11]). Nonetheless, the Malthusian theory of "environmental limits" might be seen as the origins for the concept of sustainable development [11].

The concept of sustainable development was introduced to overcome environmental challenges [11]. Before the World Commission on Economic Development (WCED) came up with the definition for sustainable development, there were already significant precursors to it. However, the report by WCED [13], titled Our Common Future, is often seen as the starting point for the concept of sustainable development. Recently, the United Nations defined a set of 'sustainable development' goals (SDGs) [14,15] due to a multitude of negative phenomena such as climate change, political instability, scarcity of resources, and cultural conflict, but also positive ones such as economic integration, and technological innovations $[11,16]$. The organization initiated the agenda 2030 for sustainable development including 17 SDGs and 169 associated targets [15]. It is a universal agenda, which can be seen as a plan of action for people, planet, and prosperity in order to reach peace and freedom for everyone. Figure 1 illustrates the blueprint of the 17 SDGs.

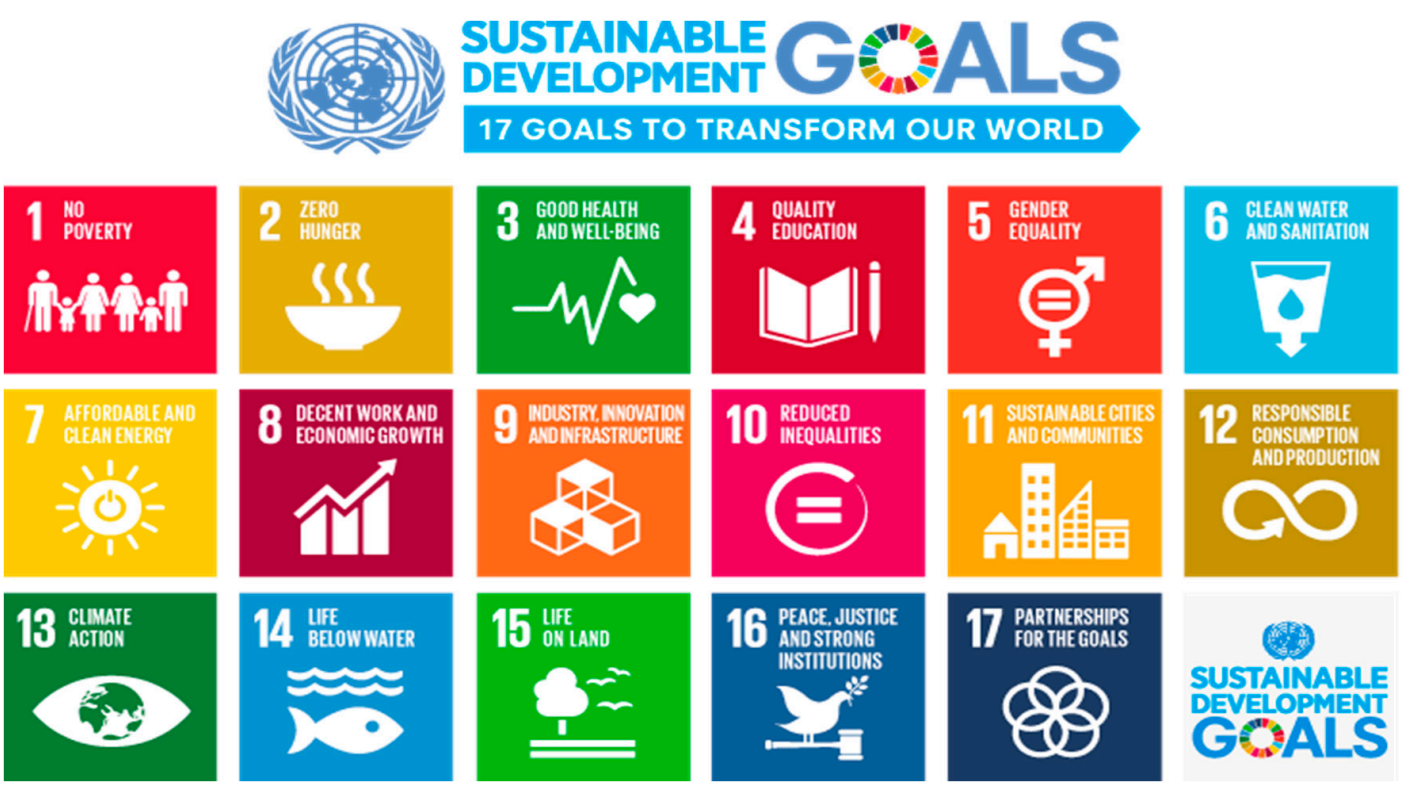

Figure 1. The 17 sustainable development goals by the United Nations [15].

The objective of this article is to review the state of the art in innovation management and sustainability, and especially identify key links between the two research fields. In order to reach this objective, the authors respected the guidelines for systematic literature reviews [17] and addressed the following research questions:

RQ1: What is the volume, growth trajectory, and geographic distribution of the knowledge base?

RQ2: What are the most influential journals, authors, and articles on innovation in sustainable development?

RQ3: What is the intellectual structure of the field's knowledge base?

RQ4: How did the intellectual structure of the field evolve? 
This review applies science mapping techniques $[18,19]$ in order to assess the knowledge base of innovation in sustainable development. This review will provide a systematic, bibliometric synthesis of research trends identified in the SCOPUS-indexed publications. According to Zupic and Čater [18] science mapping is a relatively new research method for literature reviews. The method focuses on the tangibility of a specific knowledge base [20]. Hallinger and Suriyankietkaew [21] defined four dimensions in order to analyze a body of literature:

- Size: Refers to the quantity of gathered knowledge.

- Time: Refers to the publication evolution within a research field.

- Space: Indicates the geographic source of publications within a domain.

- Composition: Covers the intellectual composition of a knowledge base.

Notably, all four dimensions are important in order to analyze the structure of a knowledge base. Therefore, in this review, the composition of the literature was assessed regarding the structure of journal publications, authorship, document influence, and topics in the body of knowledge.

This review sets itself apart from other reviews on innovation in sustainable development based on two features: First, it sought to develop a comprehensive view of the literature from 1985 to 2018 and secondly, this review applies science mapping techniques for the first time in this combined research field.

\section{Background of the Review}

This section will give an overview of innovation and sustainable development and how the two are connected. First, innovation is explained in the broader sense, followed by the concept of sustainable development.

\subsection{Innovation}

Central to competitive advantage and superior performance in a knowledge-based economy is the ability and capacity to innovate continuously [22]. The term innovation can be traced back to the Austrian economist Joseph A. Schumpeter [23], who defines it as "the doing of new things or the doing of things that are already done, in a new way" (p. 151). The Oslo Manuel by the OECD [24] gives one of the most cited definitions for the term innovation [25]: "An innovation is the implementation of a new or significantly improved product (good or service), or process, a new marketing method, or a new organizational method in business practices, workplace organization or external relations" (p. 46). Indeed, the literature about innovation is abundant with many different definitions for the term [26-29].

Innovation can be categorized in different ways, i.e., source of value creation [30], types of innovation [31], subject of innovation [32], content of innovation [33], classification of innovation [34], and through different aspects, i.e., perspectives or levels [35], degree of innovativeness [32], and origins of innovation $[31,35]$. Furthermore, an innovation can concern a product or service, a process, a new supply source, a new market, or a new way of how to organize the business [30,31,33-36].

Understanding the relevance of the five dimensions and the role of innovations towards achieving the SDGs, can facilitate their development and in more general support sustainable development. Sachs [14] states that the world will require new technological breakthrough innovations in order to increase the living standards for each individual and to protect the ecology. Technological change as well as (private) investment in renewable energies are identified by Sachs [14] as key factors to the road of sustainability. Ashford and Hall [2] also argue that the path to more sustainability goes through the creative destruction populated by Schumpeter [37,38]. In the theory of economic innovation, the gale of creative destruction delineates the process of industrial adaptation to a new environment, which revolutionizes the economic structure, and which replaces the old one [38]. In the context of sustainable development, Ashford and Hall [2] argue that innovation, especially technological innovation, will help to fight against pollution and waste, as well as allowing a better energy allocation. Technology 
innovation is defined by Ashford and Sachs as "the first commercially successful application of a new technical idea" (p. 273).

In the business context, Chesbrough and Crowther [39] state that ideas from outside of the organization emerge as a new driver for innovations and thus for sustainable growth. This model is referred to by the authors as 'open innovation'. However, Chesbrough and Crowther [39] note that open innovation is not a replacement for R\&D departments but instead "conclude that Open Innovation has utility as a paradigm for industrial innovation beyond high tech to more traditional and mature industries" (p. 229). Therefore, the idea of Open Innovation might be beneficial to support sustainable development in the business landscape and might help to reach the SDGs defined by the United Nations.

Technological innovation is the process where a company focuses its resources and capabilities on the technical aspect of the product, service, or process that serves as a source of innovation in order to increase its market competitiveness. Business innovation is of a broader magnitude and affects the whole organization, which is also known as business model innovation [40].

\subsection{Sustainable Development}

In 1987, the term 'sustainable development' gained attention [41] after the publication of the report Our Common Future by the WCED [13]. The WCED [13] defines sustainable development as the "development that meets the needs of the present without compromising the ability of future generations to meet their own needs". The action plan to achieve the SDG by the United Nations is based on the universal declaration of human rights, the international human rights treaties, the Millennium Declaration, and the 2005 world summit outcome [14,15]. The objective is to reach the SDGs by 2030 [15].

According to Schmidt-Bleek [42], in order to reach sustainable development, we need a ten-fold improvement in material resources as well as energy efficiency. Furthermore, Ashford and Hall [2] add the following improvement requirements: "adequate reduction in exposure to toxic substances; significant opportunities for stable, rewarding, and meaningful employment with adequate purchasing power; and an adequate level and distribution of essential goods necessary for economic welfare" (p. 271). Those improvements can be attained by innovative solutions. The SDGs and its associated targets by the United Nations are characterized as [15]:

"integrated and invisible, global in nature and universally applicable, taking into account different national realities, capacities and levels of development and respecting national policies and priorities" (p. 15).

The goals and targets will be incorporated by each government independently, in line with their own national planning process, policies, and strategies [15]. Furthermore, it is of high relevance to recognize the relationship between the SDGs and the dimensions of sustainable development, which are economic, social, and environmental. Sustainable development varies in definition, but all tend to refer to the triple bottom line approach of human wellbeing [14]. In Table 1 the three principles of sustainable development and its respective aim are summarized.

Table 1. Three principles of sustainable development [41].

\begin{tabular}{cl}
\hline Principle & \multicolumn{1}{c}{ Aim } \\
\hline $\begin{array}{c}\text { Environmental Integrity } \\
\text { Social Equity }\end{array}$ & $\begin{array}{l}\text { Ensures that human activities do not erode the earth's land, air, and water resources. } \\
\text { Ensures that all members of society have equal access to resources and opportunities. } \\
\text { Promotes a reasonable quality of life through the productive capacity of organizations } \\
\text { and individuals in society. }\end{array}$ \\
\hline
\end{tabular}


According to almost all societies, human wellbeing lies in the combination of environmental integrity, social equity, and economic prosperity. However, the implementation and the specification of those principles varies depending on the country. In a global context, a common understanding of the environmental, social, and economic objectives would help to overcome the biggest humanitarian challenges such as extreme poverty. In the following table the SDGs by the United Nations are listed.

\subsection{Sustainable Growth}

The terms sustainable growth and sustainable development have become familiar, although their meaning is still not clearly defined (Daly, 1990). When looking up the term in the dictionary, growth is referred to "the process of increasing in size" (Oxford dictionary online). According to Daly (1990), growth is the quantitative increase in physical scale, whereas development covers the qualitative aspect, such as unfolding of potentialities.

Often sustainable growth is also referred to sustainable economic growth, meaning that a country follows a specific rate of growth which it can sustain without creating further major economic issues, particularly for the next generation to come. Sustainable growth means growth that is repeatable, ethical, and responsible. This is not only true for a country, but can also be transferred to a business. The objective for a business is to grow just as fast as it can be maintained by the production capacity, thus finding the optimum sustainable growth rate (SGR) is key. The SGR indicates the maximum growth rate that a company can sustain without having to increase financial leverage.

According to Ashford and Hall [2] the biggest barriers to achieve sustainability is "(1) the failure to envision, design, and implement policies that achieve co-optimization, or the mutually reinforcing of social goals, and (2) entrenched economic and political interest that gain from the present system and advancement of its current trend" (p. 270). Therefore, the implementation of the SDGs defined by the United Nations in each participating country is a challenge. With those barriers, Ashford and Hall [2] propose to 'open-up' trade regulations, industrial policies, as well as environmental law and policies. The authors suggest expanding and integrating the practice of multi-purpose policy design. Furthermore, the study by Ashford and Hall [2] demonstrate that sustainable development requires technological innovation in order to succeed. Those technological innovations can be met through different channels, such as health, economic, environmental, safety, and labor market regulations. Therefore, technological as well as business innovation are the key areas of this research.

\section{Methods and Materials}

For this paper, a bibliometric review method was applied. According to Nerur, Rasheed, and Natarajan [43] as well as White and McCain [44] bibliometric approaches have become a reliable method for citation analysis, text, and data mining. Bibliometrics now has the ability to generate an understandable analysis of knowledge accumulation. Applications of the method in management literature show insightful results, e.g., for road mapping [45], business model innovation process [46], and digital business models [47]. The first step is the clarification of the search criteria and the identification of the sources. For this purpose, the authors applied the PRISMA (Preferred Reporting Items for Systematic Reviews and Meta-Analyses) guidelines developed by Moher et al. [48]. Moher et al. [48] state that the aim of this guideline "is to help authors improve the reporting of systematic reviews and meta-analyses" (p. 265). The SCOPUS database served to identify sources by using Boolean operators. The second step implies the extraction of the data from SCOPUS. The third step is about the data analysis through bibliometric methods. The fourth and last step is then the interpretation and visualization of the results according to the research questions (see section four). Figure 2 shows an overview of the methodical approach in order to reach the objective of the research. 


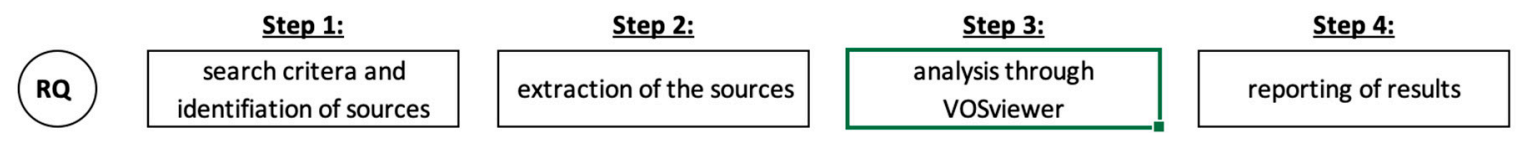

Figure 2. Methodical approach to reach the objective of the research.

The source of the term bibliometrics can be traced back to the French author Paul Otlet and his oeuvre Le livre et la mesure-Bibliometrie [49]. Bibliometrics is derived from the French language and it originates from the terminology "Bibliometrie". The definition given by Pritchard [50] is that bibliometrics is "the application of mathematical and statistical methods to books and other media of communication". Various software tools are available such as Sitkis [51], VOSviewer [52], and BibExcel [53] in order to perform the bibliometric analysis. As highlighted by Zupic and Čater [18], bibliometric software tools "take raw bibliographic data (e.g., an export from Web of Science or SCOPUS), perform bibliometric calculations, and calculate the similarity matrices between items (documents, authors, journal and words)". With the help of bibliometric methods in science mapping, it is possible to link individual papers to one another [18]. According to Boyack and Klavans [54], science mapping is a combination of visual representations and classifications schemes. Therefore, it allows to show and highlight the dynamics and structures in a scientific research field. The following criteria are first identified by science mapping techniques: Who (authors), what (keywords), where (locations), when (year of publication), and with whom (collaborative networks). Acknowledged by numerous authors [18-21], bibliometric review methods allow for a more comprehensive analysis of a specific research field. An often pointed out advantage is the possibility to handle a large amount of data and to convert it into valuable information. To achieve this, bibliometric analyses use a quantitative approach. This especially permits to introduce some rigor in the composition of the literature within the given field of research. According to Zupic and Čater [18] bibliometric reviews allow one to find main trends in a research field, describe the development and the structure of a research domain, and furthermore synthesize elements that helps to define the intellectual structure of the knowledge base. Therefore, such reviews help to gain an extensive and broad overview of the network and structure of a field of interest.

The underlying review applied science mapping, a form of bibliometric analysis, to explore the knowledge base of innovation in sustainable development (ISD) based on the four dimensions (size, time, space, and composition) defined above.

\subsection{Search Criteria and Identification of Sources}

For this review, the SCOPUS database was used to identify potential sources. It is a widely used database to create datasets for systematic reviews of research $[18,55]$. SCOPUS is the largest abstract and citation database of peer reviewed literature. It includes books, scientific journals, and conference proceedings [56]. Compared to other scientific databases such as the Web of Science, SCOPUS has a broader coverage [57] and hence makes it a better option for a research review in management [58]. Furthermore, according to Zupic and Čater [18], the handling of the data exportation from SCOPUS is simpler and better fits bibliometric software than other databases such as Google Scholar" ${ }^{\mathrm{TM}}$. An advantage of SCOPUS is that "it contains data for all authors in cited references, making author-based citation and co-citation analysis more accurate" [18]. Numerous reviews have also favored SCOPUS as the database for the bibliometric analysis of a specific research field [21,44-46,59]. Schiavi and Behr [60] acknowledge that the choice for this database is justified since SCOPUS has a great impact in the academic literature due to its access to a wide range of journals and sources in all kinds of knowledge domains (e.g., business management).

This review uses only journal articles, since a higher degree of quality control can be reached [21,45]. The subject area was limited to studies in social science, business, and decision making due to the topical foci of this review. Articles listed in the SCOPUS database were reviewed in alignment with the research questions and overall objective. The timeframe for our document search was limited from 
1985 to 2018. The first publications appeared in 1985. The extraction of the dataset was conducted at the beginning of the year 2019 .

An initial search for "Sustainable Development" AND Innovat* yielded 15,678 documents. A second pass of the SCOPUS database using "Sustainable Growth" AND Innovat* resulted in another 549 documents. "Sustainable growth" was included as a search term, because an initial scan of literature related to ISD revealed a large involvement of innovation towards the development of a lasting growth strategy. However, a search of similar terms is likely to contain some overlaps and duplicates. Therefore, using the Boolean operators "AND" and "OR" the two searches were combined into one search string to query the titles, keywords or abstracts:

TITLE-ABS-KEY("Sustainable Development" OR "Sustainable Growth") AND TITLE-ABS-KEY(innovat*)

The search resulted in 16,040 documents published in the period from 1985-2019. Applying the following initial screening criteria reduced the original dataset by 10,140 to 5900 documents.

Exclusion and Inclusion (i.e., limit to ... ) Criteria:

1. Exclude all Source Types that are NOT Journal (8028 documents excluded);

2. Exclude all Document Types that are NOT Article (1355 documents excluded);

3. Limit to articles written in English (519 documents excluded);

4. Exclude Publication Year 2019 (238 documents excluded).

After scanning a sample of the 5900 abstracts identified by the search, it became apparent that a large portion of the articles were not relevant to the purpose of the analysis, since those studies did not focus on innovation related to sustainable development or sustainable growth. The dataset was further reduced by limiting the Subject Areas to "Social Sciences", "Business, Management and Accounting" and "Decision Sciences". The three subject areas were selected to focus the data collection to the most relevant journal articles. An initial screen of other subject areas showed that there was no clear link between innovation and sustainable development or growth. Moreover, the keyword field was excluded from the search string, to obtain a better fit according to the research purpose.

After excluding non-relevant subject areas, the pre-screened dataset was reduced by another 4210 to 1690 documents published in the period from 1985 to 2018.

Relevance filter:

1. Limit to the Subject Areas "SOCI", "BUSI" and "DECI". (2455 documents excluded);

2. Exclude the Keywords field from the search (i.e., using the following search string "TITLE-ABS ("Sustainable Development" OR "Sustainable Growth") AND TITLE-ABS (innovat*)" and apply all aforementioned exclusion/inclusion criteria and relevance filters) (1755 documents excluded).

The focus of this review is to include articles that discuss or examine sustainable development in connection with innovation. Therefore, articles were excluded that examined sustainable development, but did not explicitly relate to innovation in their work. Prior extraction, the results were reviewed for relevance and inclusion/exclusion and criteria mentioned above. After screening the dataset, a total of 14,346 documents were eliminated, which resulted in a final sample size of 1690 articles (Figure 3).

\subsection{Data Extraction}

In order to use the dataset extracted from SCOPUS for the bibliometric analysis, we downloaded the data as a .csv (comma-separated values) file and a .bib (BibTeX Bibliographical Database) file. The extracted data comprised the author name, author affiliation, article title, keywords, abstracts, and multiple citation data. The data in the .csv file format is used with the VOSviewer Software and the .bib file format is used with Bibliometrix (R Studio). 


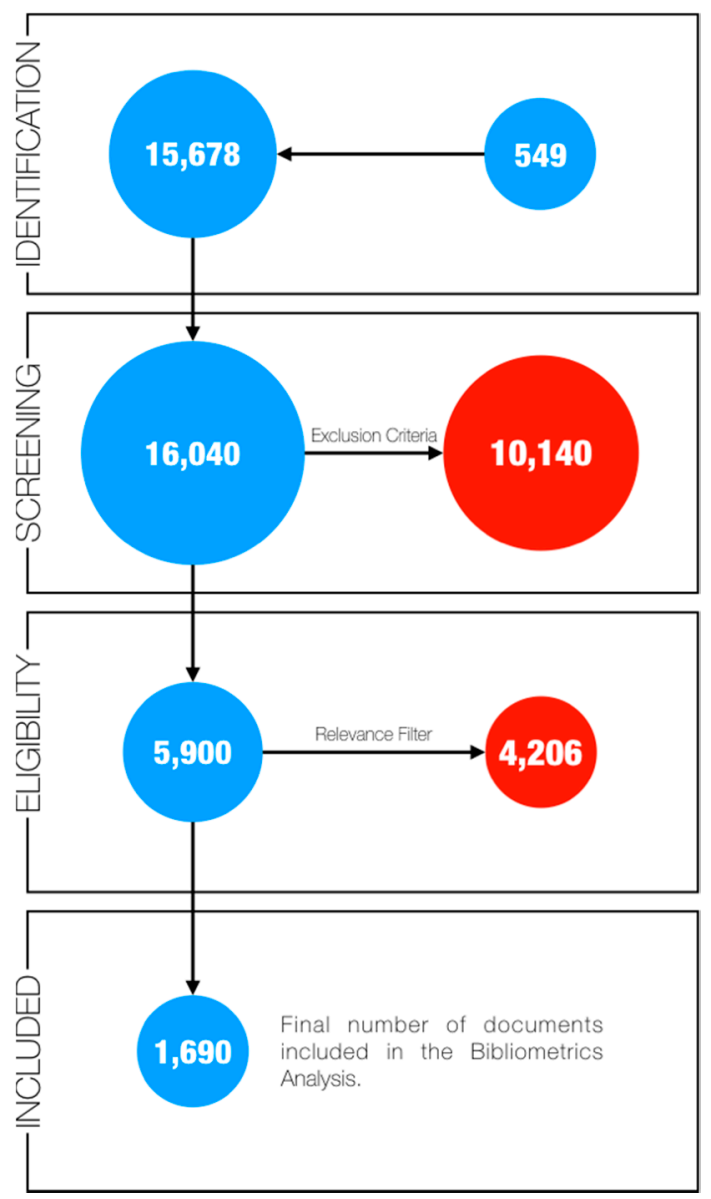

Figure 3. Preferred Reporting Items for Systematic Reviews and Meta-Analyses (PRISMA) flow diagram: Detailing steps in the identification and screening of sources [48].

\subsection{Data Analysis}

The data analyses in this review relied on descriptive statistics and bibliometric analysis. The base feature of the body of literature such as volume, development, and geographical distribution was documented with the help of descriptive analyses, which was conducted partly in Bibliometrix (R Studio) and partly with the tabulation software. Bibliometric analysis was carried out through the VOSviewer software in order to visualize the dataset on innovation in sustainable development. Van Eck and Waltman [52] describe VOSviewer as a software tool for visualizing data in so called network maps. This software permits a more accurate visualization of the underlying data than maps created through a multi-dimensional approach [52]. Given that, for this review, the VOSviewer software is used, which applies a visualization of similarities (VOS) method to construct so called 'network maps' that can represent links between the different characteristics of the investigated literature base [61]. Table 2 gives an overview of the performed analysis and visualizations through VOSviewer.

Table 2. VOSviewer manual description of analyses types [62].

\begin{tabular}{cl}
\hline Type of Analysis & \multicolumn{1}{c}{ Description by VOSviewer MANUAL } \\
\hline Co-authorship analysis & The relatedness of items is determined based on their number of co-authored documents. \\
Citation analysis & The relatedness of items is determined based on the number of times they cite each other. \\
Co-citation analysis & The relatedness of items is determined based on the number of times they are cited together. \\
Bibliographic coupling & The relatedness of items is determined based on the number of references they share. \\
\hline
\end{tabular}


As can be seen from Table 3, bibliometric analysis can employ citation or co-citation analysis. Citation analysis relates to the number of times a document in the dataset has been cited by other documents in the same database [21]. Co-citation allows to gain different insights into a knowledge base $[18,44]$. Zupic and Čater define co-citation analysis "as the frequency with which two units are cited together" (p. 431). This means that the more two articles are cited together, the more those two articles are related. Co-citation analysis can take three different forms: Journal co-citation analysis (JCA), author co-citation analysis (ACA), and document co-citation analysis (DCA). Hallinger and Suriyankietkaew [21] summarized the advantage of co-citation analysis: "This capability to include influential documents that may be located outside of the reviewed database, and even outside of SCOPUS, enables co-citation analysis to provide complementary insights to those offered by traditional citation analysis" (p. 7).

Table 3. Top ten journals publishing literature on innovation in sustainable development (ISD) ranked by numbers of articles.

\begin{tabular}{|c|c|c|c|c|c|}
\hline Rank & Journal & No. of Publications & Total Citations & $h \_$index & $\overline{\text { g_index }}$ \\
\hline 1 & Sustainability (Switzerland) & 168 & 937 & 13 & 25 \\
\hline 2 & Journal of Cleaner Production & 119 & 3083 & 29 & 52 \\
\hline 3 & $\begin{array}{l}\text { International Journal of Sustainability in } \\
\text { Higher Education }\end{array}$ & 29 & 547 & 12 & 23 \\
\hline 4 & Technology Forecasting and Social Change & 22 & 481 & 14 & 21 \\
\hline 5 & Business Strategy and the Environment & 19 & 705 & 11 & 19 \\
\hline 6 & $\begin{array}{l}\text { International Journal of Innovation and } \\
\text { Sustainable Development }\end{array}$ & 18 & 74 & 5 & 8 \\
\hline 7 & Quality. Access to Success & 16 & 40 & 2 & 6 \\
\hline 8 & Sustainable Development & 16 & 282 & 12 & 16 \\
\hline 9 & $\begin{array}{l}\text { African Journal of Science, Technology, } \\
\text { Innovation and Development }\end{array}$ & 15 & 7 & 1 & 1 \\
\hline 10 & Espacios & 14 & 1 & 1 & 1 \\
\hline
\end{tabular}

The advantage of using co-citation analysis is that it covers a broader range of publications than initially extracted from SCOPUS. This type of analysis also comprises all documents in the reference list of documents incorporated in the review dataset. Henceforth, a much larger dataset than initially covered by SCOPUS alone can be seized.

\section{Results}

The extracted dataset from SCOPUS contains 1690 articles from 667 journals published between 1985 and 2018. Overall, the extracted articles were published by over 4000 different authors, of which only 456 documents were single-authored. The results of the bibliometric analysis based on this dataset are presented according to the foci of the four research questions. The research questions will be each answered independently, starting with RQ1 in Section 4.1, RQ2 in Section 4.2, RQ3 in Section 4.3, and RQ4 in the last Section 4.4 .

\subsection{Volume, Growth Trajectory, and Geographic Distribution of ISD Literature}

This section takes a birds-eye view on discussing the knowledge base for literature relevant to innovation and sustainable development (ISD). By investigating the volume, growth trajectory and geographic distribution of the literature this section is aimed at answering the first research question stated in Section 1.

A total of 1690 journal articles related to innovation and sustainable development (ISD) represent a large knowledge base. The growth trajectory can be separated in three major periods (Figure 4). From 1985 to 2005 a slow and steady growth can be reported. The first period can be seen as the foundation stage of ISD literature with 177 published articles. The most used keywords during this period are industrial ecology, sustainable cities, and city planning. Some of the most cited publications discuss methods and tools to build a competitive edge for a sustainable development of organizations and 
industries. From the year 2005 to 2012 a more accentuated increase of the literature can be observed with a total of 477 articles. Most used keywords during this period are environmental management, cleaner production, competitiveness, corporate social responsibility, and eco-efficiency. As reflected by the top keywords of that period, companies started to think more sustainable, and sustainability in general became vital not only to conserve the environment, but also for organizational sustainable growth. During this period the top five most cited papers were published $[53,54]$, discussing the role of innovation in corporate sustainable development. It is worth mentioning that in general, there has been an increasing interest in innovation, which might also explain the greater interest. In addition, the term innovation might have a different descriptor, thus not captured by the research. The last period can be delimited from 2012 to 2018, where with 1035 publications an intense growth of the knowledge base can be recorded. Highly used keywords of this period are Sustainable Development Goals, Eco-Innovation, Social-Innovation, CSR, and Entrepreneurship, further supporting the importance of innovation in achieving ecological and economical sustainability. Topics discussed by the top five cited papers in that period ranges from business model innovation to co-creation and strategic planning for sustainable development. At the peak in 2018 a new high with 290 published articles was reached. This is certainly due to the Internet and the fast promulgation of content, as well as to a more critical and environmentally focused society. Figure 4 shows the growth trajectory over a period of more than 30 years, where a greater interest can be noted in the past decade.

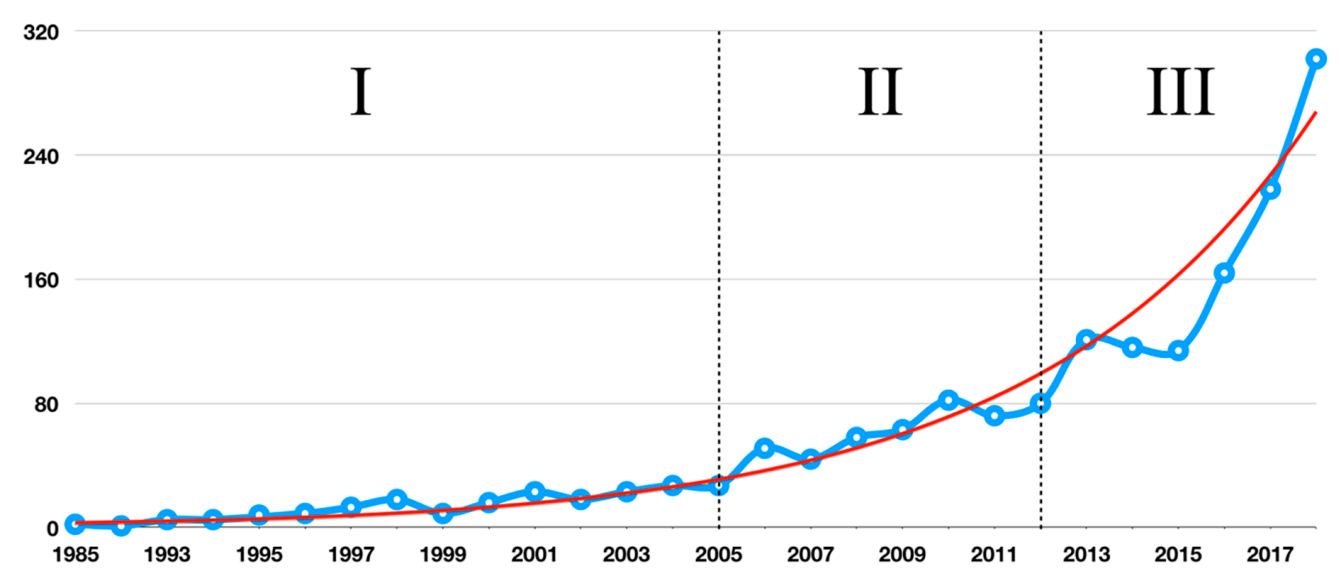

Figure 4. Growth trajectory of the innovation in sustainable development literature, $1985-2018$ ( $\mathrm{n}=1637)$.

The world map in Figure 5 shows the top most productive countries, based on the author affiliations, that publish ISD journal articles. Europe led by the UK seems to be the most productive region when it comes to ISD articles. Figure 5 also compares the academic articles by country (top 10 countries) with the corresponding total and average citations obtained by those articles.

The ISD literature contains 50 or more contributions from countries situated in Europe (e.g., Spain, Italy, Germany), Asia (e.g., China), North America (USA, Canada), and Oceania (e.g., Australia). The country with the most publications is the UK (202), followed by China (196), USA (177), The Netherlands (95), and Germany (94).

Although China offers a large contribution to the full corpus of ISD articles, it does not represent a high impact on the field, as can be seen by the total and average citations received (Figure 5). Canada (85) and the USA (177) account for 73\% from a total of 359 articles that originate from the American continents (North and South). The knowledge production of Anglo-American Societies (i.e., USA, UK, Canada, Australia, and New Zealand) account for 559 articles. Those five countries account for about a quarter (25.6\%) of the articles in this research field. According to Hallinger [59], this characterizes a common trend in publications on management, social science, and decision science literature. However, it should not be considered that those countries have a greater interest in ISD literature, but rather interpreted as a feature of academic articles in global management journals. Indeed, a great collaboration can be noted between the individual countries, as shown in Figure 6. 


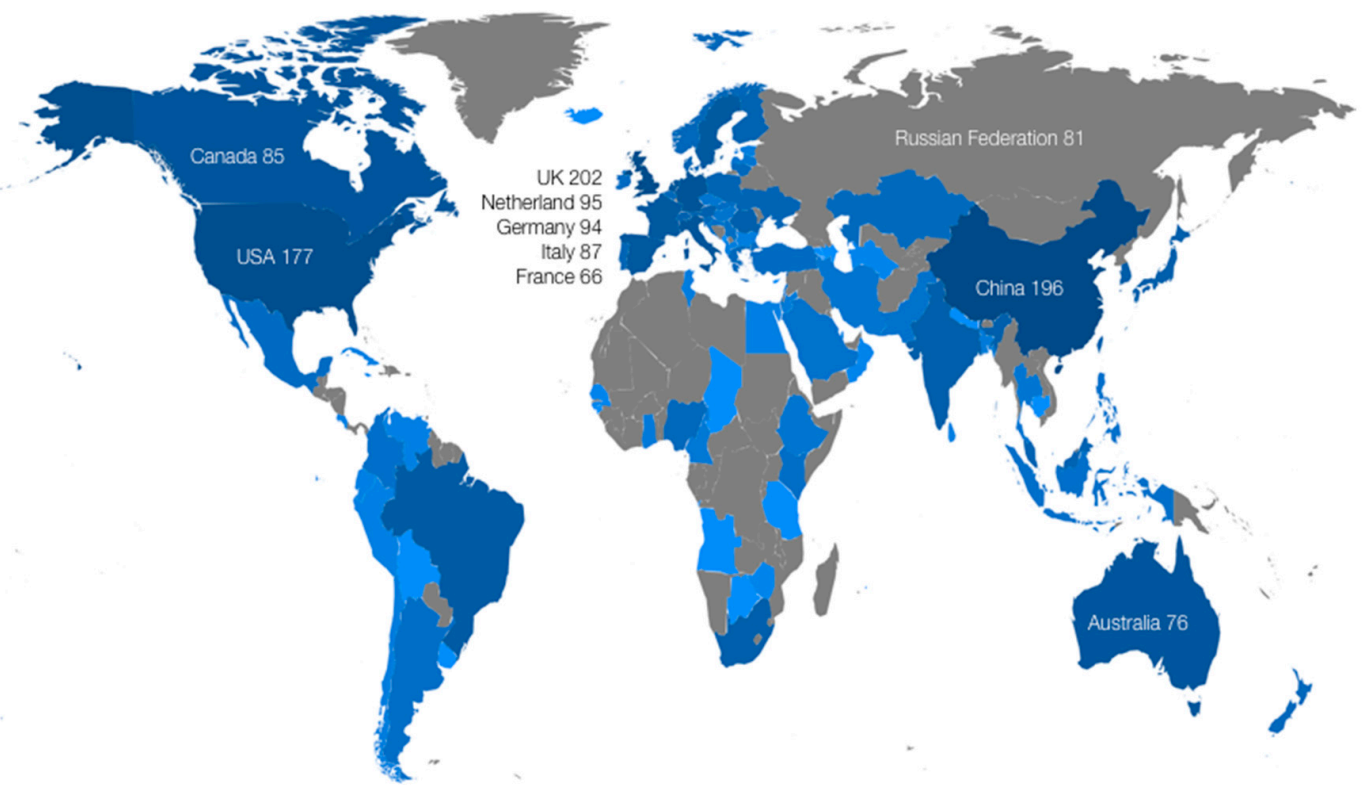

\begin{tabular}{|c|c|c|c|c|c|c|c|c|c|c|c|}
\hline \multicolumn{4}{|c|}{ Top 10 Countries by Total Publications } & \multicolumn{4}{|c|}{ Top 10 Countries by Total Citation (TC) } & \multicolumn{4}{|c|}{ Top 10 Countries by Average Citations (AC) } \\
\hline Country & Articles & TC & AC & Country & Articles & TC & AC & Country & Articles & TC & AC \\
\hline United Kingdom & 202 & 5404 & 26.75 & United Kingdom & 202 & 5404 & 26.75 & Netherlands & 95 & 3661 & 38.54 \\
\hline China & 196 & 1667 & 8.51 & Netherlands & 95 & 3661 & 38.54 & Belgium & 18 & 668 & 37.11 \\
\hline United States & 177 & 3638 & 20.55 & United States & 177 & 3638 & 20.55 & Canada & 85 & 2427 & 28.55 \\
\hline Netherlands & 95 & 3661 & 38.54 & Canada & 85 & 2427 & 28.55 & Sweden & 60 & 1607 & 26.78 \\
\hline Germany & 94 & 1775 & 18.88 & Germany & 94 & 1775 & 18.88 & United Kingdom & 202 & 5404 & 26.75 \\
\hline Italy & 87 & 706 & 8.11 & China & 196 & 1667 & 8.51 & Norway & 22 & 525 & 23.86 \\
\hline Canada & 85 & 2427 & 28.55 & Sweden & 60 & 1607 & 26.78 & Switzerland & 35 & 766 & 21.89 \\
\hline Russian Federation & 81 & 201 & 2.48 & Spain & 65 & 1288 & 19.82 & Denmark & 28 & 577 & 20.61 \\
\hline Australia & 76 & 1215 & 15.99 & Australia & 76 & 1215 & 15.99 & United States & 177 & 3638 & 20.55 \\
\hline France & 66 & 886 & 13.42 & France & 66 & 886 & 13.42 & Hong Kong & 20 & 405 & 20.25 \\
\hline
\end{tabular}

Figure 5. Academic production by country, from 1985-2018.

russian federation

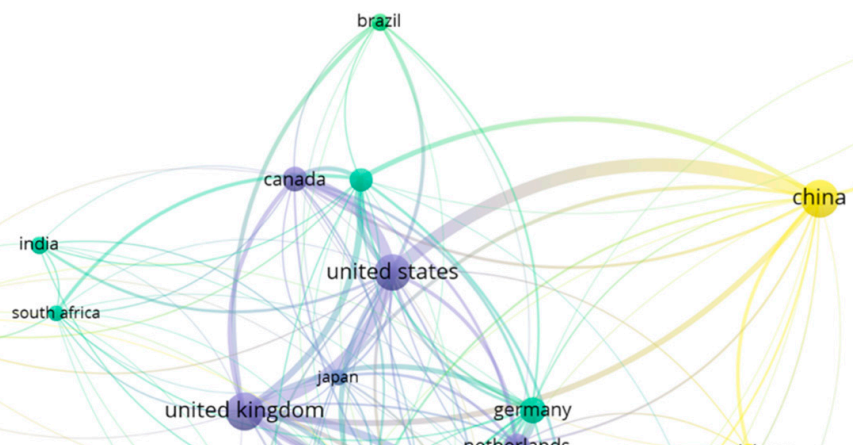

\begin{tabular}{lrrr}
\multicolumn{4}{c}{ Most Productive Regions } \\
\hline \multicolumn{1}{c}{ Region } & Articles & \multicolumn{1}{c}{ TC } & \multicolumn{1}{c}{ AC } \\
\hline Europe & 1147 & 20,733 & 460.62 \\
Anglo-American & 559 & 12,832 & 99.64 \\
Asia & 452 & 3,978 & 214.74 \\
America & 359 & 6,956 & 272.79 \\
Australia \& NZ & 95 & 1,363 & 99.64 \\
Africa & 94 & 487 & 87.43 \\
Middle-East & 37 & 187 & 47.73 \\
\hline
\end{tabular}

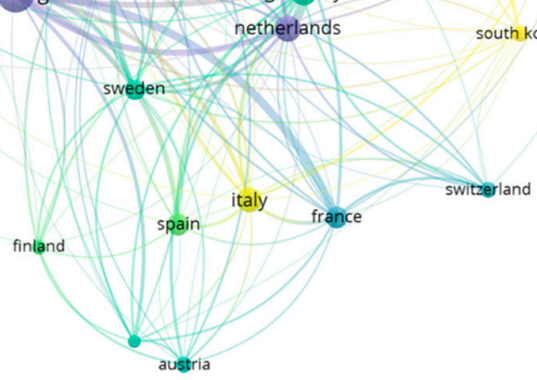

Figure 6. Country co-authorship (VOSviewer: Minimum 25 documents and 100 citations per country, Time overlay). 
The size of the nodes represents the number of articles published by the country. The greater the node size of the country, the more articles the country published. Figure 6 only represents countries with at least 25 published articles, which reached together a minimum of 100 citations. The links between the countries stands for the number of co-authored papers between the connected countries. Thus, the thicker the line, the more articles the two countries collaborated on. Yellow color represents most recent publications and shows that China, Taiwan, and South Korea have only recently joined the research ISD area.

\subsection{Analysis of Influential Journals, Authors, and Publications}

This section analyzes the most influential journals, authors, and publications in the ISD literature. Six hundred and sixty-seven journals published out of the total of 1690 articles were about ISD. By far, the most publications is the journal Sustainability (168), followed by the Journal of Cleaner Production (119), and far behind ranks the International Journal of Sustainability in Higher Education (29). The top ten journals account already for about $26 \%$ of the dataset with 436 articles (Table 4). The distribution of articles across all those journals shows the diverse and large interest in this research field and reflect the many different facets SD can incorporate: It might be important for education systems, single companies, industry sectors, but also to whole nations, or even to the world. The diversity of the academic articles on ISD is indicated by a surprising mix of journal foci, represented in domains such as sustainability, business and management, education management, management and strategy, as well as innovation and natural science. There are many international journals, but also more region-specific journals can be found, such as the African Journal of Science, Technology, Innovation and Development, Mediterranean Journal of Social Science or Asian Social Science. Interestingly, specific journals focusing on a specific part of the environment, such as the mountains, are also represented in the database (i.e., Mountain Research and Development).

Table 4. Rank order of the ten most cited authors on ISD literature, 1985-2018.

\begin{tabular}{ccccc}
\hline Rank & Author & Total Citations & Documents & ACY \\
\hline 1 & Smith A. & 988 & 8 & 61.75 \\
2 & Seyfang G. & 888 & 3 & 49.33 \\
3 & Bansal, P. & 868 & 1 & 62.00 \\
4 & Chesbrough, H. & 784 & 1 & 60.31 \\
5 & Crowther, A. K. & 784 & 1 & 60.31 \\
6 & Schot, J. & 603 & 2 & 54.82 \\
7 & Geels, F. W. & 585 & 1 & 53.18 \\
8 & Kemp, R. & 453 & 3 & 17.42 \\
9 & Wagner, M. & 394 & 5 & 43.78 \\
10 & McCormick, K. & 378 & 3 & 63.00 \\
\hline
\end{tabular}

This result shows that a great part of the articles about ISD are printed in high-quality journals, thus a high research level quality in this domain can be assumed. However, when looking at the citation index, journals such as Espacios and the African Journal of Science, Technology, Innovation and Development, are not highly ranked.

Next, in order to find clusters of journals, we applied the journal co-citation analysis with the help of the bibliometric software tool VOSviewer. Due to representation purposes, we set the threshold to a minimum of 100 citations of a published article in a given journal. Figure 7 shows the journals with the highest number of citations. The nodes symbolized represent the quantity of co-cited articles issued by a single journal. Kovacevic and Hallinger [63] state that the "proximity of nodes reflects the extent to which co-citations are derived from those journals" (p. 7). This denotes a larger measure of influence than direct citation impact. Journals which are grouped into the same color clusters tend to publish articles around a similar topic or with an equivalent interest [18]. VOSviewer generated for the JCA network structure concerning the literature on ISD shows four basic clusters: 
- The green cluster represents journals which are situated mainly in the general business and management field.

- The yellow cluster focuses on international journals around education and sustainability.

- The red cluster is comprised of journals in the ecology and environment sector as well as in the general energy consumption.

- The blue cluster represents transdisciplinary journals with a focus on technology and research policy.

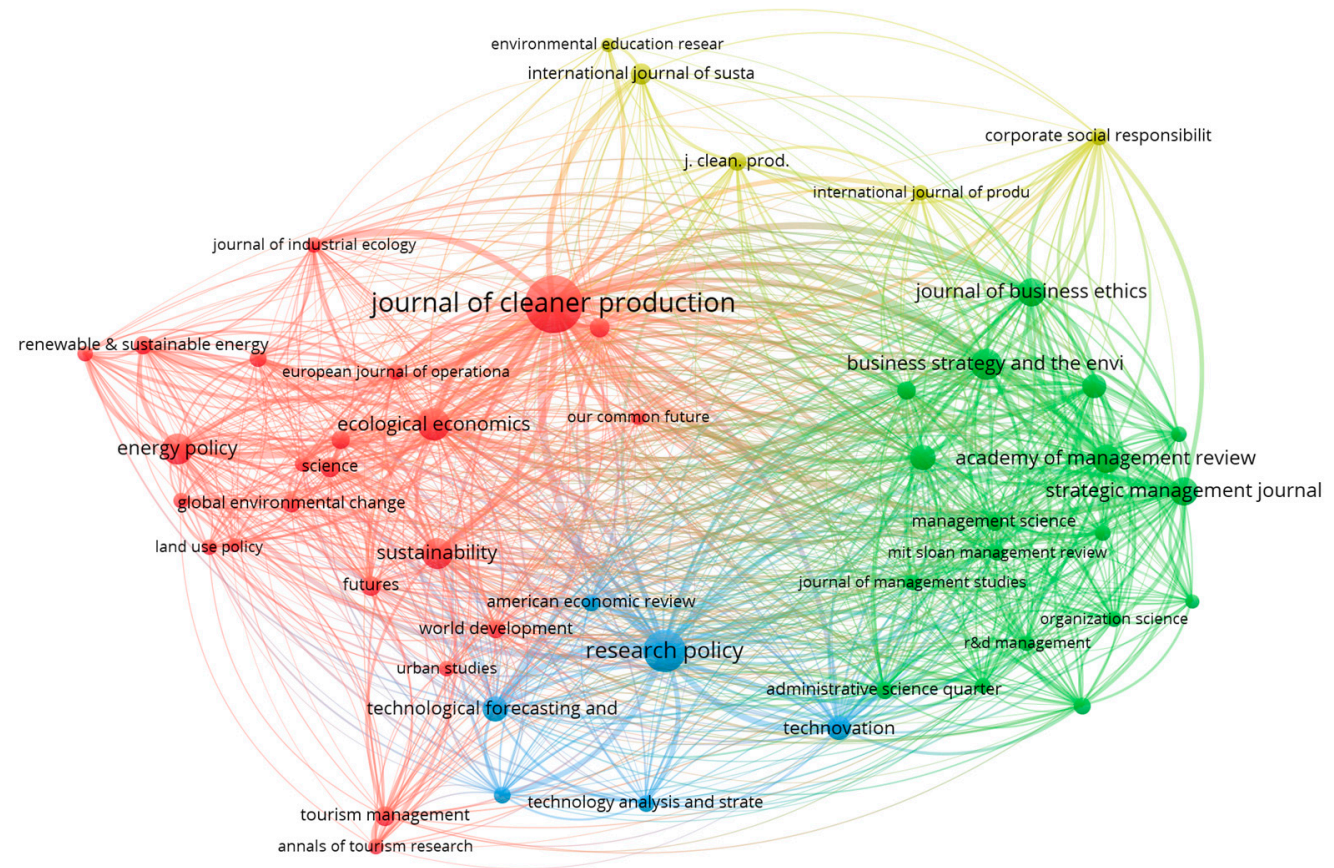

Figure 7. Journal co-citation network of the ISD literature (top 50, threshold 100 citations).

Overall, the JCA demonstrates that the studies in the ISD field are internationally oriented and mainly focused on innovation and sustainable development in the business context. However, the analysis indicates a different focus in research (e.g., technology, policy, tourism, manufacturing). The top 10 articles in Table 5 represent published articles relevant to the business context and therefore support the accuracy of the collected data.

Another strength of bibliometric analysis is the possibility to distinguish the key authors in a given research field $[57,58]$. Table 4 gives an overview of the ten main authors according to the SCOPUS-indexed publications and citations. The authors Smith and Seyfang do not appear in one of the top journals. Bansal (Strategic Management Journal), Chesbrough, and Crowther (R\&D Management) as well as Wagner (Business Strategy and the Environment) appear in the green cluster of the journal co-citation network. Wagner also published in a journal located in the yellow cluster (Journal of Cleaner Production), in which McCormick (Journal of Cleaner Production) also appears. Schot and Geels (Technology Analysis and Strategic Management) and Schot (Research Policy) published in journals situated in the blue cluster.

The most productive authors in the research field of ISD are J. Wang (8), Y. Wang (8), Watanabe (8), Zhang (8), Smith (8), and X. Wang (7). However, Table 5 indicates that the most influential authors in this research field, as measured by total SCOPUS-citations, are Smith (988), Seyfang (888), Bansal (868), Chesbrough (784), and Crowther (784).

The analysis of highly cited documents in the ISD literature are represented in Table 6. 
Table 5. Ten most cited articles in the ISD literature, 1985-2018.

\begin{tabular}{|c|c|c|c|}
\hline Rank & Author(s) & Article Title & Cites \\
\hline 1 & Bansal (2005) & $\begin{array}{l}\text { Evolving sustainably: A longitudinal study of corporate } \\
\text { sustainable development. }\end{array}$ & 868 \\
\hline 2 & $\begin{array}{l}\text { Chesbrough and } \\
\text { Crowther (2006) }\end{array}$ & $\begin{array}{l}\text { Beyond high tech: Early adopters of open innovation in } \\
\text { other industries. }\end{array}$ & 784 \\
\hline 3 & Schot and Geels (2008) & $\begin{array}{l}\text { Strategic niche management and sustainable innovation } \\
\text { journeys: Theory, findings, research agenda, and policy. }\end{array}$ & 585 \\
\hline 4 & Seyfang and Smith (2007) & $\begin{array}{l}\text { Grassroots innovations for sustainable development: } \\
\text { Towards a new research and policy agenda. }\end{array}$ & 553 \\
\hline 5 & $\begin{array}{l}\text { Seyfang and Haxeltime } \\
\qquad(2012)\end{array}$ & $\begin{array}{l}\text { Growing grassroots innovations: Exploring the role of } \\
\text { community-based initiatives in governing sustainable } \\
\text { energy transitions. }\end{array}$ & 310 \\
\hline 6 & Matos and Hall (2007) & $\begin{array}{l}\text { Integrating sustainable development in the supply chain: } \\
\text { The case of life cycle assessment in oil and gas and } \\
\text { agricultural biotechnology. }\end{array}$ & 299 \\
\hline 7 & $\begin{array}{l}\text { Boons, Montalvo, Quist, } \\
\text { and Wagner (2013) }\end{array}$ & $\begin{array}{l}\text { Sustainable innovation, business models and economic } \\
\text { performance: An overview. }\end{array}$ & 252 \\
\hline 8 & $\begin{array}{l}\text { Kemp, Parto and Gibson } \\
\text { (2005) }\end{array}$ & $\begin{array}{l}\text { Governance for sustainable development: Moving from } \\
\text { theory to practice. }\end{array}$ & 244 \\
\hline 9 & Bos-Brouwers (2010) & $\begin{array}{l}\text { Corporate sustainability and innovation in SMEs: Evidence } \\
\text { of themes and activities in practice. }\end{array}$ & 216 \\
\hline 10 & $\begin{array}{l}\text { Yam, Guan, Pun, and } \\
\text { Tang (2004) }\end{array}$ & $\begin{array}{l}\text { An audit of technological innovation capabilities in Chinese } \\
\text { firms: Some empirical findings in Beijing, China. }\end{array}$ & 215 \\
\hline
\end{tabular}

The results of Table 6 shows, that the most highly cited articles are from Bansal (868 cites), Chesbrough (784 cites), Schot (585 cites), Seyfang (553 cites). These authors are Anglo-American scholars, which highlights again the predominance from those countries.

Table 6. Rank order of the ten most highly co-cited ISD documents, 1985-2018.

\begin{tabular}{cclc}
\hline Rank & Author & \multicolumn{1}{c}{ Document Title } & Co-Cites \\
\hline 1 & Hart (1995) & A natural-resource-based view of the firm & 33 \\
\hline 2 & $\begin{array}{c}\text { Sharma \& Vredenburg } \\
(1998)\end{array}$ & $\begin{array}{l}\text { Proactive corporate environmental strategy and the development } \\
\text { of competitively valuable organizational capabilities }\end{array}$ & 24 \\
\hline 3 & Bansal \& Roth, (2000) & Why companies go green: a model of ecological responsiveness & 20 \\
\hline 4 & Barney (1991) & Firm resources and sustained competitive advantage & 20 \\
\hline 5 & $\begin{array}{c}\text { Schaltegger \& Wagner } \\
(2011)\end{array}$ & $\begin{array}{l}\text { Sustainable entrepreneurship and sustainability innovation: } \\
\text { categories and interactions }\end{array}$ & 20 \\
\hline 6 & $\begin{array}{c}\text { Eiadat, Kelly, Roche } \\
\text { \& Eyadet (2008) }\end{array}$ & $\begin{array}{l}\text { Green and competitive? An empirical test of the mediating role of } \\
\text { environmental innovation strategy }\end{array}$ & 17 \\
\hline 8 & Bansal (2005) & $\begin{array}{l}\text { Evolving sustainability: a longitudinal study of corporate } \\
\text { sustainable development }\end{array}$ & 15 \\
\hline 9 & $\begin{array}{c}\text { Carrillo-Hermosilla, } \\
\text { Del Rio \& Konnola (2010) }\end{array}$ & $\begin{array}{l}\text { Diversity of eco-innovations: Reflections from selected case } \\
\text { studies }\end{array}$ & 14 \\
\hline 10 & $\begin{array}{c}\text { Chiou, Chan, Lettice } \\
\text { \& Chung (2011) }\end{array}$ & $\begin{array}{l}\text { The influence of greening the suppliers and green innovation on } \\
\text { environmental performance and competitive advantage in Taiwan }\end{array}$ & 14 \\
\hline
\end{tabular}

The traditional citation analysis can be supplemented with another dominant method of science mapping, the co-citation analysis [64]. Therefore, we next applied the document co-citation analysis. This analysis examines which articles in the ISD dataset have been co-cited with articles situated in the reference list of the other ISD documents [21]. It is noteworthy that those documents do not need to be in the initial database extracted from SCOPUS, since this type of analysis links back to the reference list of each individual article downloaded. Therefore, a much broader database than primarily covered by SCOPUS can be seized and hence analyzed, which may even go beyond academic research articles and journals, depending on the authors use of references. Table 6 ranks the ten most highly co-cited ISD articles. 
The document co-citation analysis (DCA) does not confirm the trends in the citation analysis. The reference list of each individual article downloaded shows overall a different interest in publications. The publications of those references discuss more the fundamentals of an organization and might be acknowledged as a basis for the sustainable development and innovation activities. There is a tremendous amount of interest and publications related to supply chain and sustainability related themes, but that goes beyond the scope of this article. The co-cited articles focus a great deal on a companies' resources and on the strategy, thus their competitive positioning, whereas the citation analysis of the most cited articles mainly have their focus specifically on sustainable development.

\subsection{Intellectual Structure of the ISD Knowledge Base}

The third research question delves into the intellectual structure underlying the ISD domain. Therefore, we applied the author co-citation analysis (ACA), which is commonly used in science mapping $[18,57,58]$. Van Eck and Waltman [52] state that the bibliometric software tool VOSviewer is an appropriate tool for this analysis. The benefits of using VOSviewer is that it calculates author co-citations as well as generates a co-citation map that maps similarities in the literature of the authors together.

The scholars are represented by nodes, which vary in size. An author with a high impact shows a bigger node than an author with less influence. The links between the authors represent the co-citation by the other author. A thick link signifies a high number of co-citations. VOSviewer does not only represent the influence of each scholar and the relationships between them, but also groups authors with common theoretical perspectives and lines of inquiry into colored clusters. Those clusters each represent one 'School of Thought', which mirror common theoretical understandings [18,44]. The author co-citation network map for the ISD literature distinguishes four 'Schools of Thought' (i.e., the yellow, the red, the blue, and the green clusters). Five of the top ten authors-Smith, Seyfang, Schot, Kemp, and Geels (see Table 5)—are in the green cluster, three of the top ten-Chesbrough, Wagner, and Bansal-are in the red cluster and the other two are represented in neither one. However, the interpretation of such a network map requires a certain amount of tacit knowledge [21], in order to depict and categorize the different clusters.

Figure 8 shows the 150 most highly co-cited authors in the co-citation network. Out of 69,696 authors in the author co-citation network, 207 met a threshold of a minimum of 30 author co-citations. From this network, Kemp (251), Smith (203), Porter (171), Schaltegger (148), Geels (134), and Rennings (130) are the most highly co-cited authors. Noteworthy, some academics (e.g., Hoogma, Fare, Schumpeter) included in the author co-citation list did not appear in the review dataset. The explanation for their inclusion lies in the impact of their broader conceptual and empirical contributions to the knowledge base of sustainability, innovation, and management, which was then cited by authors in the ISD dataset.

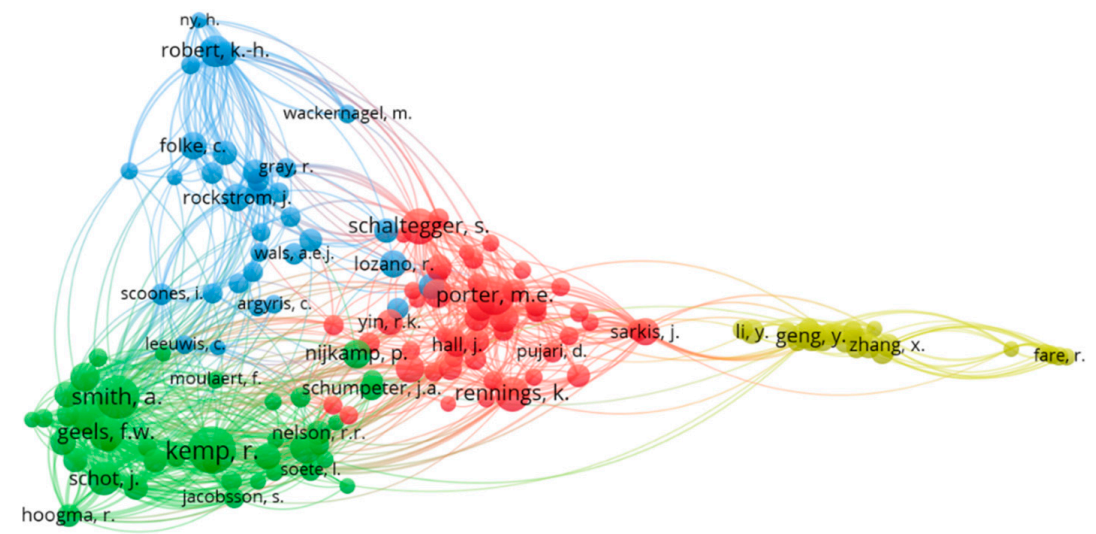

Figure 8. Author co-citation analysis of the ISD literature, 1985-2018 (threshold 30 citations, display 150 authors). 


\subsection{Topical Foci of the Innovation in Sustainable Development Knowledge Base}

The last research question sought to illuminate the topical trend in the research field of ISD. Therefore, the next science mapping technique applied is the keyword co-occurrence analysis or also known as co-word analysis. Zupic and Čater [18] describe that "when words frequently co-occur in documents, it means that the concepts behind those words are closely related ... The output of co-word analysis is a network of themes and their relations that represent the conceptual space of a field" (p. 435). Consequently, this type of analysis allows to identify the topical foci of a specific research field. For the co-word analysis we again used VOSviewer and set the threshold to at least 10 cases of a co-occurring keyword. In order to get a better picture of the associated keywords related to innovation, sustainable development, and sustainability, we excluded those keywords from the co-word analysis. The most co-occurring keywords in the database were planning (105), education (83), environmental protection (64), environmental management (60), economics (55), decision making (51), economic growth (50), and climate change (50). The unexpected dominance of the keyword 'planning' might be explained by the fact that the steps to innovation for sustainable development have to be arranged beforehand. Furthermore, due to the prevalence of 'environmental' in the keywords, it is assumed that the intellectual base of the research domain has emerged from it. The network co-word occurrence visualization map shows five generic clusters of keywords (Figure 9).

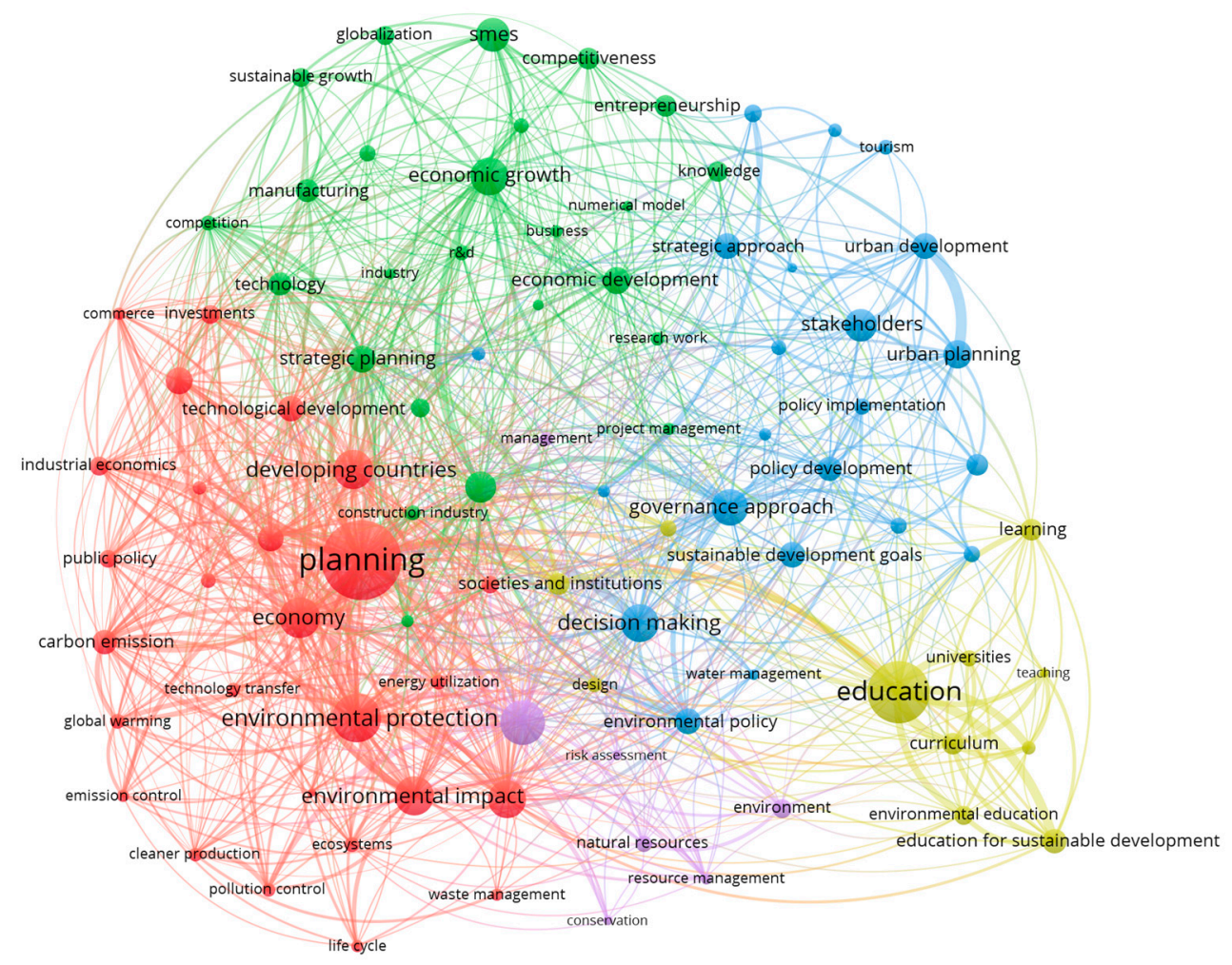

Figure 9. Network keyword co-occurrence map for innovation in sustainable development, 1985-2018 (threshold ten, display 100, excluding innovation, sustainable development, and sustainability).

The clusters in Figure 9 represent the topical foci of the keywords. The yellow cluster focuses on education and learning. The blue cluster relates to urban development and governance. The red cluster is linked to the environment and the possible planning possibilities in order to control pollution. The purple cluster concentrates on resource management and the green cluster is connected to strategy as well as economic growth and development. 
The co-word analysis is also helpful to detect the 'research front' of a specific domain [18,54]. According to Price [65], the 'research front' represents the growing tip of the literature. Since the environment of a research field changes constantly, it is recognized that the research front is dynamic as academics try to respond to those movements. Publications of new findings alter the topical trends in a research field, which can be highlighted by the identification of the research front.

By generating a temporal keyword co-occurrence overlay map through VOSviewer, it is possible to uncover the research front of the ISD literature. The visual representation given by the temporal keyword co-occurrence map shows on the one hand the similarities, and on the other hand categorization of themes based on their prevalence across a specific timespan $[19,62]$. The timeline goes from purple (2010) over green (2013) to yellow (2015). The color of the clusters represents the relative popularity of a keyword in a specific year (i.e., planning-yellow-2015). The co-word map for ISD is shown in Figure 10.

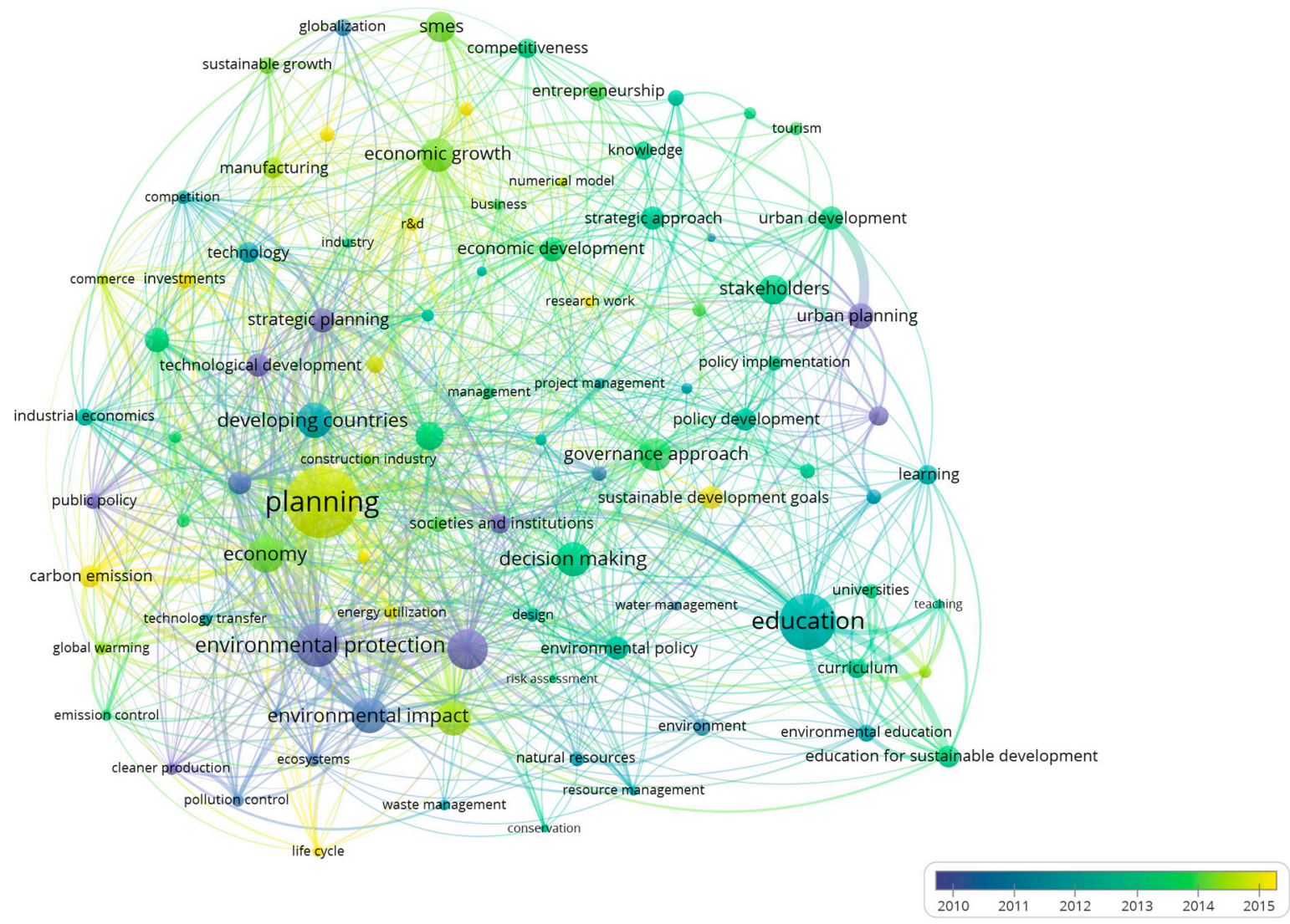

Figure 10. Temporal overlay on a keyword co-word occurrence map for innovation in sustainable development, 1985-2018 (threshold ten, display 100, excluding innovation, sustainable development, and sustainability).

From this co-word map, the following research front in ISD, classified by recency and strength of interest, can be outlined-sustainable development goals (see United Nations), planning, carbon emission, investments, economic growth, developing countries and environmental protection and impact. Those keyword occurrences in yellow means a recent higher interest in academic research in those topics, thus we can deduct inter alia from the linkage of the keywords that the research in ISD is heading towards the investment in sustainable development programs probably concentrated in developing countries in order to counter the environmental impact of the pollution issue. The awareness of a change necessity to more sustainable development in different areas is recognizable, since the overlay map shows keywords such as industry, education, tourism, or urban development. 


\section{Discussion}

In this review we used science mapping to uncover influential authors, articles, and journals on ISD, as well as to reveal the origin of the knowledge base and enhance our understanding of the intellectual structure of the research field. We employed bibliometric analysis and considered 1690 SCOPUS-indexed articles published between 1985 and 2018. The next two sections give an overview of the limitations of the review and propose our understanding of the findings.

\subsection{Interpretation and Implications of the Findings}

Interestingly, the combined term 'Circular Economy' did not emerge in the keyword analysis. The similarities and differences between the two terminologies Circular Economy and sustainability are not clear and indefinite [8].

The knowledge base started to appear in the academic sphere around 1985, but it was not until 2015 that the interest in this topic took off, where a high increase of publications can be noted. The greater interest may be due to the higher mediatization of the general bad development the earth takes and on the recent release of the SDGs by the United Nations. A future growth of this research field can be thus expected, where solutions to diverse development issues will be proposed, i.e., ocean cleaning, combating pollution through e-mobility.

The paucity of works from African countries as well as from the Middle East is on the first sight not explainable with the data at hand and the software package we used. However, an explanation might be given by the fact that they have in relative terms fewer academic institutions than developed societies. The temporal map shows increasing numbers of publications coming from Asia, a trend which is likely to continue.

Furthermore, we can deduct from the analysis that a high interest in the last couple of years around innovation in sustainability emerged and that Anglo-American societies contributed the most to the knowledge base. A high interest in this topic resides in the developed countries, in contrast to the underdeveloped countries, which might be affected most by the outcome of the application of the SDGs, yet thus far, exhibit less attention.

Innovation in general, but also innovation in the context of sustainable development affects many parts of human life and should thus be treated with more concern. The keyword co-occurrence analysis (Figures 9 and 10) covers the three dimensions of sustainable development: Economic, social, and environmental $[15,41]$. This also mirrors the SDGs by the United Nations, where goals eight and nine represent the economic dimension, goals four, five, and 16 the social dimension, and goals six, seven, $12,13,14$, and 15 the environmental dimension. The dimension 'environmental' was also recognized as the basis of sustainable development in the keyword co-occurrence network. The topical foci of ISD given by the temporal overlay on the keyword co-occurrence map also reflects the resonance of the report by the United Nations about sustainable development. Therefore, it is safe to say that the keyword analysis also represents the three dimensions of sustainable development. What is striking is that most keywords also occur in the United Nations report 'Transforming our World: The Agenda for Sustainable Development' (e.g., developing countries, world, economic growth, environmental policy, education, renewable energy, technological development, climate change, industrial development, global warming, ecosystem). It seems that the research front is in alignment with the SDGs, and that innovation, especially linked to sustainable development, has great potential to accelerate human progress. According to Sachs [14], the pressure to take action is on a global as well as on local levels, and that different earth systems such as the carbon, nitrogen, and water cycles are affected. As an example, point 44 of the United Nations report can be reviewed. It states that,

"We acknowledge the importance for international financial institutions to support, in line with their mandates, the policy space of each country, in particular developing countries." 
This phrase highlights the importance of the collaboration with financial institutions, and thus the potential investments, in order to achieve an improvement in the condition of life for individuals in developing countries. 'Investment' and 'developing countries' are also identified as keywords (see above) by the temporal overlay keyword co-occurrence map with a recent high interest. In alignment with the keyword 'planning' this makes sense and calls for planned and coordinated actions for environmental protection, and more general for sustainable development.

Goal nine needs to be highlighted in the context of innovation. This goal states that the objective by the United Nations is to "promote inclusive and sustainable industrialization and foster innovation" (p. 17). The importance of innovation to reach sustainable development is also recognized by Ashford and Hall [2], as well as in the keyword co-occurrence map. Therefore, innovation plays a major role for the direction of sustainable development.

\subsection{Limitations}

In this review we used science mapping as a means to enhance our understanding of the literature base. We first want to stress out that science mapping does not replace traditional review methods, but instead can be used as a complement. Therefore, this review can be seen as the first stage, followed by substantive research syntheses, which analyze findings from research on ISD.

Another limitation arises from the conceptualization of 'sustainable development'. The authors dealt with this limitation by also including 'sustainable growth' in the research string.

A third limitation arises from the exclusive focus on SCOPUS-indexed publications. The SCOPUS database offers a wide range of articles, more than other databases such as Web of Science, but it does not include all publications within a specific domain. Indeed, the overall literature for innovation in sustainable development is broader than considered in this review, however the application of co-citation analyses somewhat reduced this limitation. This type of bibliometric analysis examines all publications included in the reference list of documents incorporated in the extracted SCOPUS database. Consequently, a much broader dataset could be examined than initially covered by SCOPUS. Moreover, conference proceedings were also excluded from the search. Conference papers are often reflecting emerging topics and themes, since a journal article takes longer time to publish.

As a last limitation, the interpretation of co-citation maps should be noticed at this point. The process is not always straightforward, which requires scholars to have a comprehensive understanding of the knowledge base in order to make sense of the output of the analysis [18]. This limitation was dealt by the expertise of the authors, but remains somewhat subjective.

\section{Conclusions}

In this review we applied science mapping to unfold the knowledge base on innovation in sustainable development. It is the first large scale systematic review attempted in this research field. For further research we would recommend analyzing more specific aspects of innovation in sustainable development, e.g., the underrepresentation of countries from Africa and the Middle East, or the increase of the ISD literature from China, although the impact is not high thus far. Research in emerging markets will be important towards fostering policy change and educating consumers and companies towards more sustainable production and consumption, with innovations helping to improve efficiency and reduce waste.

Other studies on sustainable development did not include innovation to the extent we did and focused more on sustainability itself. By sharing this research, we hope to motivate and encourage other scholars to further analyze and examine ISD in organizations as well as in societies. As problems in society (e.g., pollution, rising oceans) gain more visibility and awareness, it is expected that interest and publications related to innovations and sustainability will continue to flourish. 
Author Contributions: Conceptualization (R.V.-T. and R.S.); Methodology (R.V.-T. and A.-A.S.); Analysis (R.V.-T. and A.-A.S.); Software (R.V.-T.); Writing, reviewing (R.V.-T., A.-A.S. and R.S.); Editing (R.V.-T., A.-A.S. and R.S.); Visualization (R.V.-T., A.-A.S. and R.S.).

Funding: This research received no external funding.

Conflicts of Interest: The authors declare no conflict of interest.

\section{References}

1. Damanpour, F.; Schneider, M. Phases of the adoption of innovation in organizations: Effects of environment, organization and top managers. Br. J. Manag. 2006, 17, 215-236. [CrossRef]

2. Ashford, N.A.; Hall, R.P. The importance of regulation-induced innovation for sustainable development. Sustainability 2011, 3, 270-292. [CrossRef]

3. Jackson, T. Prosperity without Growth: Economics for a Finite Planet; Earthscan: London, UK; Earthscan: New York, NY, USA, 2009.

4. Meadows, D.H.; Randers, J.; Meadows, D.L. The limits of Growth: The 30-Year Update; Routledge: London, UK, 2004.

5. World Wide Fund for Nature (WWF). Living Planet Report 2014: Species and Spaces, People and Places; World Wide Fund for Nature: Grand, Switzerland, 2014.

6. Sen, A. Development as Freedom; Oxford University Press: Oxford, UK, 2001.

7. Prahalad, C.K. The Fortune at the Bottom of the Pyramid: Eradicating Poverty through Profits; Wharton School Publishing: Upper Saddle River, NJ, USA, 2004.

8. Geissdoerfer, M.; Savaget, P.; Bocken, N.M.P.; Hultink, E.J. The Circular Economy-A new sustainability paradigm? J. Clean. Prod. 2017, 143, 757-768. [CrossRef]

9. Sachs, J. The Age of Sustainable Development; Columbia University Press: New York, NY, USA, 2015.

10. Brennan, G.; Tennant, M.; Blomsma, F. Business and Production solutions: Closing the Loop. In Sustainability: Key Issues; Kopnina, H., Shoreman-Ouimet, E., Eds.; EarthScan; Routledge: Abingdon-on-Thames, UK, 2015; pp. 219-239.

11. Mebratu, D. Sustainability and sustainable development: Historical and conceptual review. Environ. Impact Assess. Rev. 1998, 18, 493-520. [CrossRef]

12. Pearce, D.W.; Turner, R.K. Economics of Natural Resources and the Environment; Harvester Wheatsheaf: New York, NY, USA, 1990.

13. World Commission on Environment and Development (WCED). Our Common Future; Oxford University Press: Oxford, UK, 1987.

14. Sachs, J.D. From Millennium Development Goals to Sustainable Development Goals. Lancet 2012, 379, 2206-2211. [CrossRef]

15. United Nations. Transforming Our World: The Agenda for Sustainable Development; United Nations: New York, NY, USA, 2015.

16. Boiral, O.; Baron, C. Environmental Leadership and Consciousness Development: A Case Study Among Canadian SMEs. J. Bus. Ethics 2014, 123, 363-383. [CrossRef]

17. Cooper, H.M.; Hedges, L. The Handbock of Research Synthesis; Russel Sage Foundation: New York, NY, USA, 2009.

18. Zupic, I.; Čater, T. Bibliometric Methods in Management and Organization. Organ. Res. Methods 2015, 18, 429-472. [CrossRef]

19. van Eck, N.J.; Waltman, L. Citation-based clustering of publications using CitNetExplorer and VOSviewer. Scientometrics 2017, 111, 1053-1070. [CrossRef]

20. Boyack, K.W.; Börner, K.; Klavans, R. Mapping the structure and evolution of chemistry research. Scientometrics 2009, 79, 45-60. [CrossRef]

21. Hallinger, P.; Suriyankietkaew, S. Science Mapping of the Knowledge Base on Sustainable Leadership, 1990-2018. Sustainability 2018, 10, 4846. [CrossRef]

22. Christensen, C.M. The Innovator's Dilema—When New Technologies Cause Great Firms to Fall; Harvard Business School Press: Boston, MA, USA, 1997.

23. Schumpeter, J.A. The creative response in economic history. J. Econ. Hist. 1947, 70, 149-159. [CrossRef] 
24. Organisation for Economic Cooperation and Develoment (OECD). Oslo Manual-The Measurement of Scientific and Technological Activities: Guidelines for Collecting and Interpreting Innovation Data, 3rd ed.; OECD: Paris, France; Statistical Office of the European Communities: Brussels, Belgium, 2005.

25. Mantere, S.; Schildt, H.A.; Sillince, J.A.A. Reversal of Strategic Change. Acad. Manag. J. 2012, 55, $172-196$. [CrossRef]

26. Hauschildt, J. Innovationsmanagement; Vahlen: München, Germany, 1997.

27. Hauschildt, J.; Salomo, S. Innovationsmanagement; Vahlen: München, Germany, 2011.

28. Zaltman, G.; Duncan, R.; Holbek, J. Innovations \& Organisations; Wiley: New York, NY, USA, 1973.

29. Rickards, J. Stimulating Innovation: a Systems Approach; Frances Pinter: London, UK, 2008.

30. Schumpeter, J.A. The Theory of Economic Development: An Inquiry into Profits, Capital, Credit, Interest, and the Business Cycle; Transaction Publishers: Piscataway, NJ, USA, 1934.

31. Halecker, B. New Perspective and Insights on Business Model Innovation Using Systems Thinking and Action Case Studies; University of Potsdam: Potsdam, Germany, 2016.

32. Schindler, M. Business Model Innovation within Esatablished Companies_Empirical Aspects on Drivers and Results; Dr. Kovač: Hamburg, Germany, 2014.

33. Trapp, M. Realizing Business Model Innovation-A Strategic Approach for Business Unit Managers; Springer Gabler: Wiesbaden, Germany, 2014.

34. Stampfl, G. The Process of Business Model Innovation-An Empirical Exploration; Springer Fachmedien Wiesbaden: Wiesbaden, Germany, 2016; ISBN 978-3-658-11265-3.

35. Bucherer, E. Business Model Innovation-A Guideline for a Structured Approach; Shaker Verlag: Aachen, Germany, 2010.

36. Schaller, A.A.; Vatananan-Thesenvitz, R.; Stefania, M. Business model innovation roadmapping: A structured approach to a new business model. In Proceedings of the PICMET 2018-Portland International Conference on Management of Engineering and Technology: Managing Technological Entrepreneurship: The Engine for Economic Growth, Honolulu, HI, USA, 19-23 August 2018.

37. Schumpeter, J.A. Business Cycles: A Theoretical, Historical and Statistical Analysis of the Capitalist Process; MrGraw Hill: New York, NY, USA, 1939.

38. Schumpeter, J.A. Capitalism, Socialism and Democracy; Harper Torchbooks: New York, NY, USA, 1942.

39. Chesbrough, H.; Crowther, A.K. Beyond high tech: early adopters of open innovation in other industries. R D Manag. 2006, 36, 229-236. [CrossRef]

40. Osterwalder, A.; Pigneur, Y. Business Model Generation; Wiley \& Sons: Hoboken, NJ, USA, 2010.

41. Bansal, P. Evolving sustainably: A longitudinal study of corporate sustainable development. Strateg. Manag. J. 2005, 26, 197-218. [CrossRef]

42. Florin, J.; Schmidt, E. Creating Shared Value in the Hybrid Venture Arena: A Business Model Innovation Perspective. J. Soc. Entrep. 2011, 2, 165-197. [CrossRef]

43. Nerur, S.P.; Rasheed, A.A.; Natarajan, V. The intellectual structure of the strategic management field: An author co-citation analysis. Strateg. Manag. J. 2008, 29, 319-336. [CrossRef]

44. Howard, W.; McCain, K. Visualizing a discipline: An author co-citation analysis of information science, 1972-1995. J. Am. Soc. Inf. Sci. 1998, 49, 327-355.

45. Gerdsri, N.; Kongthon, A.; Vatananan, R.S. Mapping the knowledge evolution and professional network in the field of technology roadmapping: A bibliometric analysis. Technol. Anal. Strateg. Manag. 2013, 25, 403-422. [CrossRef]

46. Schaller, A.-A.; Vatananan-Thesenvitz, R. Business Model Innovation (BMI) Process: A Systematic Literature Review with Bibliometric Analysis. In Proceedings of the PICMET 2019-Portland International Conference on Management of Engineering and Technology: Technology Management in the World of Intelligent Systems, Portland, OR, USA, 25-29 August 2019.

47. Schaller, A.-A.; Vatananan-Thesenvitz, R.; Pulsiri, N. The Rise of Digital Business Models: An Analysis of the Knowledge Base. In Proceedings of the PICMET 2019—Portland International Conference on Management of Engineering and Technology: Technology Management in the World of Intelligent Systems, Portland, OR, USA, 25-29 August 2019.

48. Moher, D.; Liberati, A.; Tetzlaff, J.; Altman, D.G. Prisma Group Preferred Reporting Items for Systematic Reviews and Meta-Analyses: The PRISMA Statement (Reprinted from Annals of Internal Medicine). Ann. Intern. Med. 2009, 151, 264-269. [CrossRef] 
49. Otlet, P. Traite de Documentation. Le Livre sur le Livre. Théorie et Pratique; Van Keerberghen: Brussels, Belgium, 1934.

50. Pritchard, J. Statistical bibliography or bibliometrics? J. Doc. 1969, 25, 348-349.

51. Schildt, H.A.; Zahra, S.A.; Sillanpaa, A. Scholarly Communities in Entrepreneurship Research: A Co-Citation Analysis. Entrep. Theory Pract. 2006, 30, 399-415. [CrossRef]

52. van Eck, N.J.; Waltman, L. Text Mining and Visualization using VOSviewer. ISSI Newsl. 2011, 7, 50-54.

53. Persson, O.D.; Danell, R.; Wiborg, J. How to use Bibexcel for various types of bibliometric. In Celebrating Scholarly Communication Studies; Aström, F., Danell, R., Larsen, B., Schneider, J., Eds.; International Society for Scientometrics and Infometrics: Leuven, Belgium, 2009; pp. 9-24.

54. Boyack, K.W.; Klavans, R. Co-Citation Analysis, Bibliographic Coupling, and Direct Citation: Which Citation Approach Represents the Research Front Most Accurately? J. Am. Soc. Inf. Sci. Technol. 2010, 61, 2389-2404. [CrossRef]

55. Mongeon, P.; Paul-Hus, A. The journal coverage of Web of Science and Scopus: a comparative analysis. Scientometrics 2016, 106, 213-228. [CrossRef]

56. Scopus. Available online: https://www.scopus.com/home.uri (accessed on 12 February 2019).

57. Moingeon, B.; Lehmann-Ortega, L. Creation and Implementation of a New Business Model. M@n@gement 2010, 13, 266-297. [CrossRef]

58. Falagas, M.E.; Pitsouni, E.I.; Malietzis, G.A.; Pappas, G. Comparison of PubMed, Scopus, Web of Science, and Google Scholar: strengths and weaknesses. FASEB J. 2007, 22, 338-342. [CrossRef]

59. Hallinger, P. Science mapping the knowledge base on educational leadership and management from the emerging regions of Asia, Africa and Latin America, 1965-2018. Educ. Manag. Adm. Leadersh. 2019. [CrossRef]

60. Schiavi, G.S.; Behr, A. Emerging technologies and new business models: a review on disruptive business models. Innov. Manag. Rev. 2018, 15, 338-355. [CrossRef]

61. Waltman, L.; Van Eck, N.J.; Noyons, E.C.M. A unified approach to mapping and clustering of bibliometric networks. J. Informetr. 2010, 4, 629-635. [CrossRef]

62. Van Eck, N.J.; Waltman, L. VOSviewer Manual; Universiteit Leiden: Leiden, The Netherlands, 2013; pp. 1-28.

63. Kovacevic, J.; Hallinger, P. Leading School Change and Improvement: A Bibliometric Analysis of the Knowledge Base (1960-2017). J. Educ. Adm. 2019, 57, 635-657. [CrossRef]

64. Vogel, R.; Güttel, W.H. The dynamic capability view in strategic management: A bibliometric review. Int. J. Manag. Rev. 2013, 15, 426-446. [CrossRef]

65. Price, D.J.D.S. Network of Scientific Papers. Science 1965, 149, 510-515. [CrossRef] [PubMed] 